\title{
Enhancement of Electrical Power Quality for Three phase AC System using fuzzy Logic Based Active Power Filter
}

\author{
Aditya Vishwakarma, R. S. Mandloi
}

\begin{abstract}
Active power filter, a good alternativeforeasing power quality problems. APF can provide an effective solution for the removal of hormonic current present in power system. The performance of shunt APF depends on technique used to generate reference current, controlling method used and topology of inverter under consideration. In this paper a fuzzy logic-based control scheme was presentedto generate reference signal for hysteresis current controller of three phase VSI. Unit templatebased control algorithm for control signal generation and fuzzy logic controller was used to replace PI controller to improve performance. The proposed system is very much capable in maintaining and improving power quality at distribution side. The shunt APF performance was analysed with SIMULATION model under balanced condition and outcome obtained satisfactory in improving the power quality.
\end{abstract}

Keyword: Active power filters (APF), Fuzzy logic controller(FLC), voltage source inverter (VSI), non-linear loads.

\section{INTRODUCTION}

In recent, the rapid utilization of power electronics devices in the distribution system increase the nonlinearity, what's more because of thatissue of harmonics become severe, which degrades the power quality of the grid risk the usual work of electrical apparatus. Traditionally passive filtersare used to restraint the harmonics. Its advantages include low cost, high efficiency and simple configuration. However, passive filters have the demerits as non-flexible compensation, size consideration and the issue of resonance [1]. Active power filters are new type of power electronics devices, that can overcome some demerits of passive filter as well as they can not only minimize harmonic but also help in reactive power management with a sensible performance-price relation. APF allows voltage harmonic compensation (Series APF), current harmonic compensation (shunt APF), and reactive power compensation of nonlinear load [2]. This work prominence on current harmonic elimination and compensation of reactive power, therefore shunt configuration has been adopted. Shunt APF injects similar current as of harmonic but inverse in phase to that specificharmonic component of load's current. In voltage source inverter (VSI) the important is to compute the current (reference) signal and generation of trigging pulse. Severalcontrolling schemes such as synchronous reference frame (SRF) or d-q theory, closed loop PI control, and instantaneous reactive power or PQ theory, etc. are used for reference current signal generation[2]-[4].

Revised Version Manuscript Received on November 15, 2019. * Correspondence Author

Aditya Vishwakarma*, Research Scholar, Department of Electrical Engineering, Shri Govindram Seksaria Institute of Technology and Science, Indore (Madhya Pradesh), India.

R. S. Mandloi, Assistant Professor, Research Scholar, Department of Electrical Engineering, Shri Govindram Seksaria Institute of Technology and Science, Indore (Madhya Pradesh), India.

(C) The Authors. Published by Blue Eyes Intelligence Engineering and Sciences Publication (BEIESP). This is an open access article under the CC BY-NC-ND license (http://creativecommons.org/licenses/by-nc-nd/4.0/)
More the number of sensors, more the complexity and more the cost. Hence the best algorithm is that which gives best result with a smaller number of sensor count.The APF performance can be controlled with different controllers like PID, Fuzzy or PI controller etc. Researcher's main effort is to change traditional controllers with some new control algorithms such as FLCalgorithm [4]. Similarly, many control algorithms like sine cosine algorithm attract research workers to use these algorithms to control the gain of traditional controller which further increase the complexity of the system [5].Artificial intelligence is key to solve complex system and make control robust. In traditional controller as PI, knowledge of controlled system was used to formulate the set of algebraic and differential equations, which narrate inputs and output relation. To get over this problem fuzzy logic-based controller can be used[6]. Fuzzy system does not require a clear perfect mathematical model, they can work with non-linearity, imprecise inputs and is more effectivethan conventional controllers [7]. The fuzzy logic system consists of membership function, there is different type of membership function which can be used out of which triangular membership function is preferred most as because of its simplicity, easy to implement symmetric along axis [8]. This paper represents a fuzzy logic-controlled system replacing PI controller with fuzzy based controller in shunt APF for improving the power quality of system by eliminating the current harmonics due to nonlinear load. The use of FLC based system is also able to reduce the complexity of system due to use of unit template algorithm which result in small in size as well as in price also. The results found with this FLC based filter are improved than that of PI controller-based system. The effectiveness of projected shunt APF was evaluated with MATLAB simulation. The total harmonic distortion (THD) outcome and IEEE standards are presented [9].

\section{SHUNT ACTIVE FILTER}

Fig. 1 reveals to a fundamental outline of shunt active power filter. System include compensation technique, nonlinear load connected to a three-phase supply. A VSI based current controlled inverter is used as APF. The shunt APF is connectedwith grid at point of common coupling (PCC). Shunt active power filter working principle is to generate harmonic currents in opposite phase but equal in magnitude to those harmonics that are present in grid. These generated harmonics current opposite in phase are injected in system that cancel outs the harmonic in system and improve the quality of power.

\section{Published By:}

Blue Eyes Intelligence Engineering \& Sciences Publication

(C) Copyright: All rights reserved. 


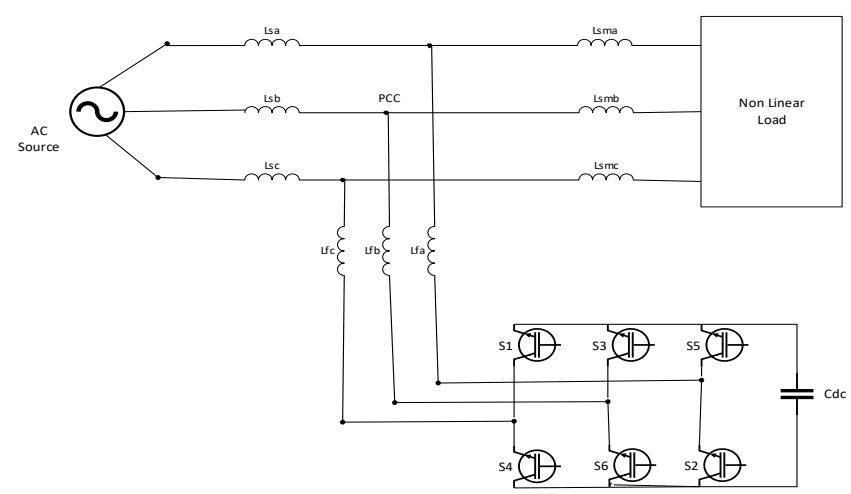

Fig.1. Shunt APF based on VSI

\section{REFERENCE CURRENT COMPUTATION}

By maintaining DCside voltage of VSI, the peak reference source current is computed. Only the current's active component is supplied by source and rest is provided by shunt APF for improving quality of power. A study of shunt APF has revealedthat, with the help of Fourier series the fundamental, load and other component can be split. The voltage, instantaneous current of source and load current be expressedas [8]:

$$
\begin{aligned}
& v_{s}(t)=V_{m} \sin \omega t \\
& i_{s}(t)=i_{L}(t)-i_{c}(t)
\end{aligned}
$$

$$
\begin{aligned}
\mathrm{i}_{\mathrm{L}}(\mathrm{t}) & =\sum_{\mathrm{n}=1}^{\infty} \mathrm{I}_{\mathrm{f}} \sin \left(\mathrm{n} \omega \mathrm{t}+\emptyset_{\mathrm{n}}\right) \\
& =I_{1} \sin \left(\omega t+\emptyset_{f}\right)+\sum_{n=2}^{\infty} I_{n} \sin \left(n \omega t+\emptyset_{n}\right) \\
& =i_{L f}(t)+i_{L h}(t)
\end{aligned}
$$

where $i_{L h}$ and $i_{L f}$ are harmonic current component and fundamental component of current respectively. Hence instantaneous power provided by supply can be written as:

$$
\begin{aligned}
p_{L}(t)= & v_{s}(t) * i_{L}(t) \\
= & V_{m} I_{1} \sin ^{2} \omega t * \cos \emptyset_{f}+V_{m} I_{1} \sin \omega t * \cos \omega t \\
& * \sin \emptyset_{f}+V_{m} \sin \omega t \\
& * \sum_{n=2}^{\infty} I_{n} \sin \left(n \omega t+\emptyset_{n}\right) \\
= & p_{\text {act }}(t)+q_{\text {react }}(t)+p_{h}(t)
\end{aligned}
$$

where $q_{\text {react., }}, p_{\text {act }}$ and $p_{h}$ are reactive power, active power and harmonic power of load. From (3), fundamental component (peak) calculated as:

$$
\begin{aligned}
p_{a c t}(t) & =V_{m} I_{1} \sin ^{2} \omega t * \cos \emptyset_{f} \\
& =\left(V_{m} \sin \omega t\right) \cdot\left(I_{1} \cos \emptyset_{f}\right) \sin \omega t \\
& =v_{s}(t) * i_{s}(t)
\end{aligned}
$$

where $I_{1} \cos \emptyset_{f}=I_{s m}$ is the peak supply side current. To includeconverter losses, switching losses, excessive loss current component will be provided by source. Hence, total current supply by source can be computed as:

$$
I_{s m}^{*}=I_{s m}+I_{\text {sloss }}
$$

Finally, the peak source current value multiplicated with unit template calculated from source voltage will provide reference current as shown in fig. 2 .

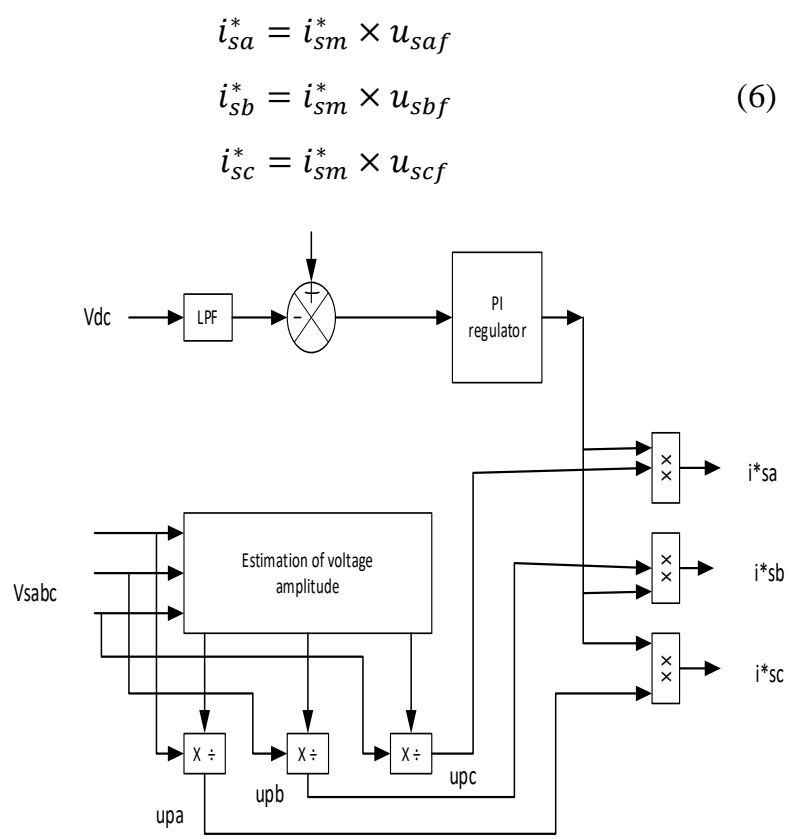

Fig.2. Control algorithm

\section{FUZZY LOGIC TECHNIQUE}

Recently, fuzzy logic technique becomes more generalthanks to it robustness, handling with parameter variation of complex system model. Fuzzy logic is another method that provide an improve trigging pulse for those VSI. Fuzzy based control is developed with a logical system that include the formation of set of verbal rules called fuzzy logic for selection of control action. It has four main steps: fuzzification, rules, inference engine and defuzzification. These steps are represented in architecture of fuzzy system as shown in fig. 3. The fuzzy logic has two inputs called change in error de and error $e$ with single output [7]. The change in error $(d e)$ and error $(e)$ used as input can express as:

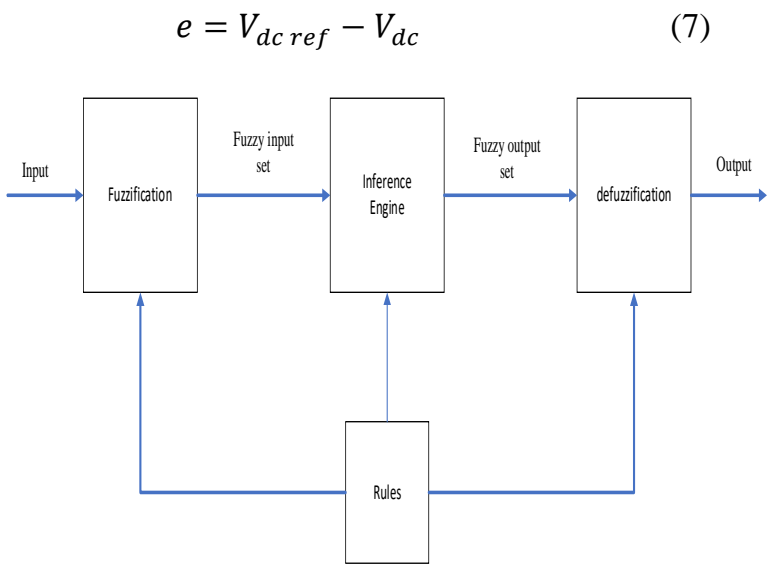

Fig.3. Block diagram of fuzzy system

Published By:

Blue Eyes Intelligence Engineering 
For this study, the triangular membership functions ( $M F)$ have been chosen for express numerical terms into linguistic terms [6]-[8]. The linguistic terms used for input and output as: negative large (NL); negative small (NS); zero (Z); positive small (PS); and positive large (PL), the rule matrix is of dimension $(5 \times 5)$ as shown in table-I, fig. 4 . Whenever the error is negative and change in error is negative or zero, the compensation will be negative. In the same manner whenever is positive and change in error positive or zero, the compensation is positive. For error as well as change in error is zero, there is no need of compensation.

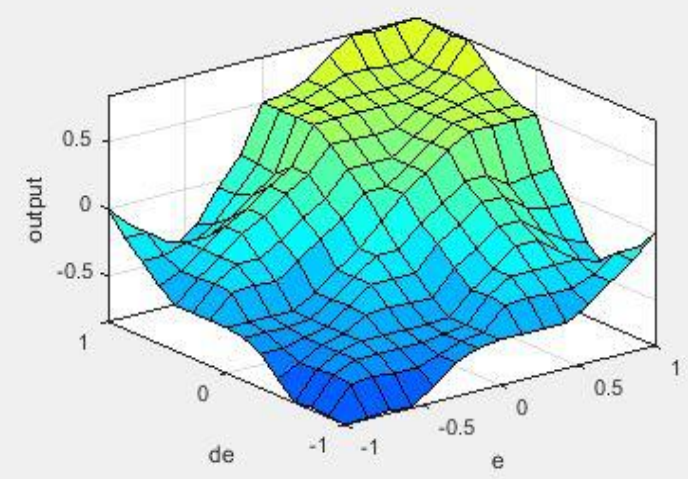

Fig.4. Surface view

Table- I: Control rule matrix

\begin{tabular}{|c|c|c|c|c|c|c|}
\hline \multirow{7}{*}{ 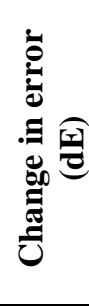 } & \multicolumn{6}{|c|}{ Error(E) } \\
\hline & & NL & NS & $\mathrm{Z}$ & PS & PL \\
\hline & NL & NL & NL & $\mathrm{N}$ & $\mathrm{N}$ & $\mathrm{ZE}$ \\
\hline & NS & NL & $\mathrm{N}$ & $\mathrm{N}$ & $\mathrm{ZE}$ & $\mathrm{N}$ \\
\hline & $\mathrm{ZE}$ & $\mathrm{N}$ & $\mathrm{N}$ & $\mathrm{ZE}$ & $\mathrm{P}$ & $\mathrm{P}$ \\
\hline & PS & $\mathrm{N}$ & $\mathrm{ZE}$ & $\mathrm{P}$ & $\mathrm{P}$ & PL \\
\hline & PL & $\mathrm{Z}$ & $\mathrm{N}$ & $\mathrm{P}$ & PL & PL \\
\hline
\end{tabular}

\section{CALCULATION FOR APF PARAMETERS}

The design of active power filter parameter mainly includes filter inductor, DC link capacitor $\left(C_{\mathrm{DC}}\right)$ and value of reference voltage $\left(V_{D C}\right.$ ref $)$. The inductor in APF is used to minimize the ripple current which is part of VSC current, and can be calculated as [2]:

$$
L_{f}=\sqrt{3} m V_{D C} /\left(12 a f_{s} I_{c r p p}\right)
$$

Where, $f s$ is the switching frequency, $m$ is modulation index $V_{d c}$ is DC bus voltage and overload factor is $a$.

Similarly, the DC capacitor design is governed by reduction and increment in DC bus voltage when load is applied and removed respectively. By the energy conservation law, we can write as:

$$
0.5 C_{D C}\left[\left(V_{D C}^{2}\right)-\left(V_{D C 1}^{2}\right)\right]=3 V_{p h}(a I) t
$$

Another method for finding DC link voltage is using second harmonic ripple voltage at DC bus of load unbalancing as;

$$
C_{D C}=I_{d} /\left(2 \omega V_{\text {DCripple }}\right)
$$

Where $I_{d}$ is active filter supply current, $\omega$ is equal to $2 \pi f$ and $\mathrm{V}_{\mathrm{DC}}$ is maximum DC ripple voltage. The proposed FLC based scheme is shown in fig. 5 .

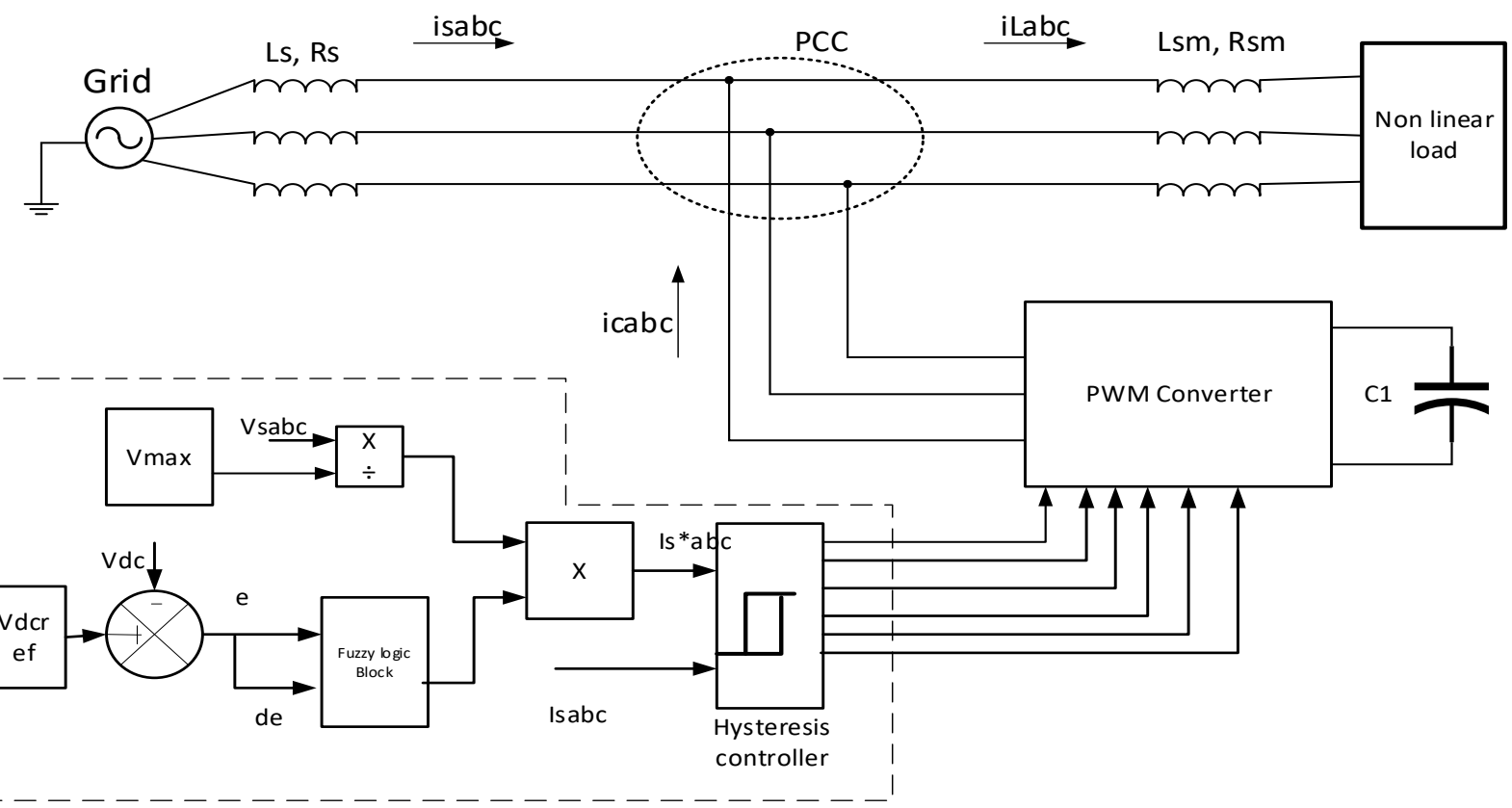

Fig.5. $\quad$ Schematic diagram of $\overline{\mathbf{F} L C} \overline{\text { Based shunt APF }}$ 


\section{CONTROLLING OF CURRENT}

Different PWM are used in different places in different aspect.Among the all hysteresis current control scheme has verifiedthe most appropriate for producing trigging signals for VSI based filter. It is generally used due to its simplicity peak current warning ability without much info about system constraints [4],[8].

The actual instantaneous source current is observed and compared reference source current produced by proposed FLC algorithm. To avoid short circuit, the positive and negative group devices are switched in opposite manner.

The switching for one phase is expressed as: if $i_{s a}<$ $\left(i_{s a}^{*}-H B\right)$, then up switch is open and low switch is closed and $\mathrm{S}_{\mathrm{a}}=1$; if $i_{s a}>\left(i_{s a}^{*}+H B\right)$, then up switch is closed and low switch is open and $S_{a}$ will becomes 0 .

Similarly, in same manner the switching sequence for all the other devices can be derived.

\section{SIMULATION RESULTS}

A simulation work developed on MATLAB/Simulink was taken in consideration to verify the projectedFLC bast Shunt active power filter. The 3-phase APF system consisting of a supply source, a VSC based inverte connecting and smoothing reactor with high non-linear load. The system parameters used in study are given in table-II. The results of fuzzy logic based APF are shown in blow figures 6 to 8 . The range of distorted source-side current is shown in fig. 6. The total harmonic distortion (THD) in source-side current before compensation due to load is $26.85 \%$ as depicted in fig. 9 which is the FFT analysis of source-side current without compensation. This, shows that the source-side current is polluted before compensation which limit the quality of power. While applying APF with FLC for compensation of harmonic, it reduces the THD in source current to $1.76 \%$ as shown in FFT analysis in fig. 10 . This shows the effectiveness of fuzzy logic based APF. The THD performance for FLC and bounds specified by IEEE 519 standards are given in table-III.

Table- II:P arameters in consideration

\begin{tabular}{|l|c|c|}
\hline Specification & Parameters & Values \\
\hline Supplysource voltage (Phase) & $\mathrm{V}_{\mathrm{s}}$ & $240 \mathrm{~V}$ \\
\hline Source frequency & $\mathrm{f}_{\mathrm{s}}$ & $50 \mathrm{~Hz}$ \\
\hline AC reactor & $\mathrm{L}_{\mathrm{ac}}$ & $1 \mathrm{mH}$ \\
\hline dc-link capacitor voltage & $\mathrm{V}_{\mathrm{dc}}$ & $700 \mathrm{~V}$ \\
\hline Dc link capacitor & $\mathrm{C}$ & $2000 \mu \mathrm{F}$ \\
\hline Filter resistor and inductor & $\mathrm{R}_{\mathrm{f}}, \mathrm{L}_{\mathrm{f}}$ & $0.05 \Omega$, \\
& & $0.8 \mathrm{mH}$ \\
\hline Smoothing resistor and inductor & $\mathrm{R}_{\mathrm{sm}}, \mathrm{L}_{\mathrm{sm}}$ & $0.5 \Omega$, \\
& & $1.5 \mathrm{mH}$ \\
\hline Switching frequency & $\mathrm{F}_{\mathrm{s}}$ & $10 \mathrm{kHz}$ \\
\hline Sampling time & $\mathrm{T}_{\mathrm{s}}$ & $50 \mu \mathrm{s}$ \\
\hline Load & $\mathrm{L}$ & $25 \Omega$, \\
& & $10 \mathrm{mH}$ \\
\hline
\end{tabular}

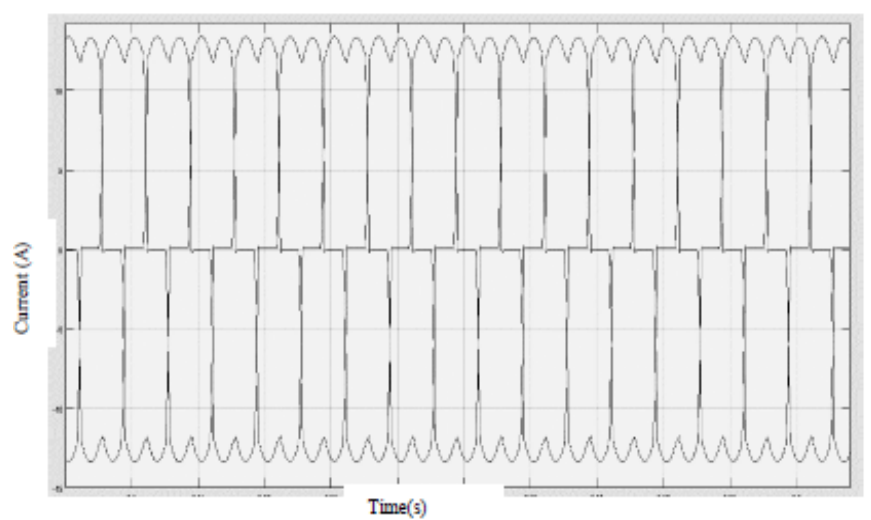

Fig.6. Source current without compensation

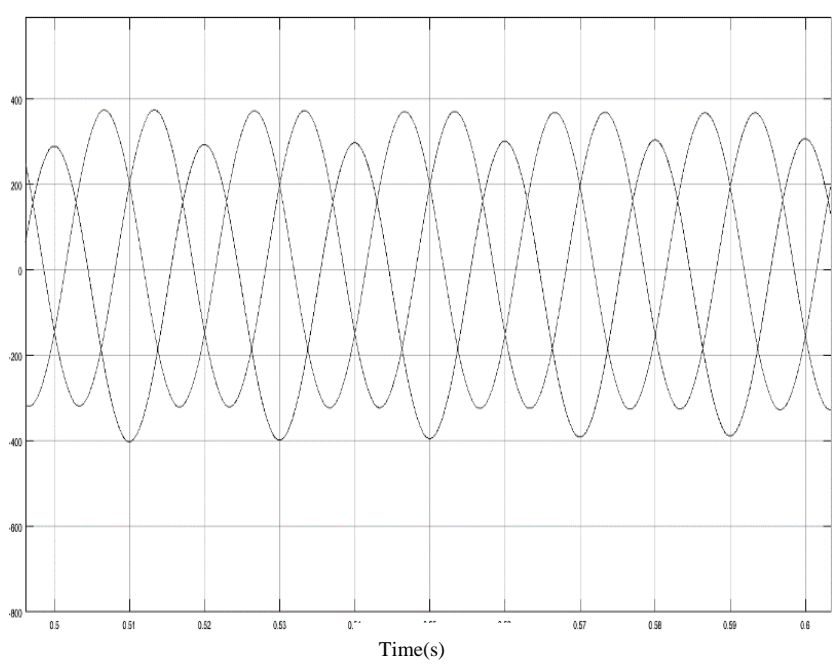

Fig.7. Compensation current

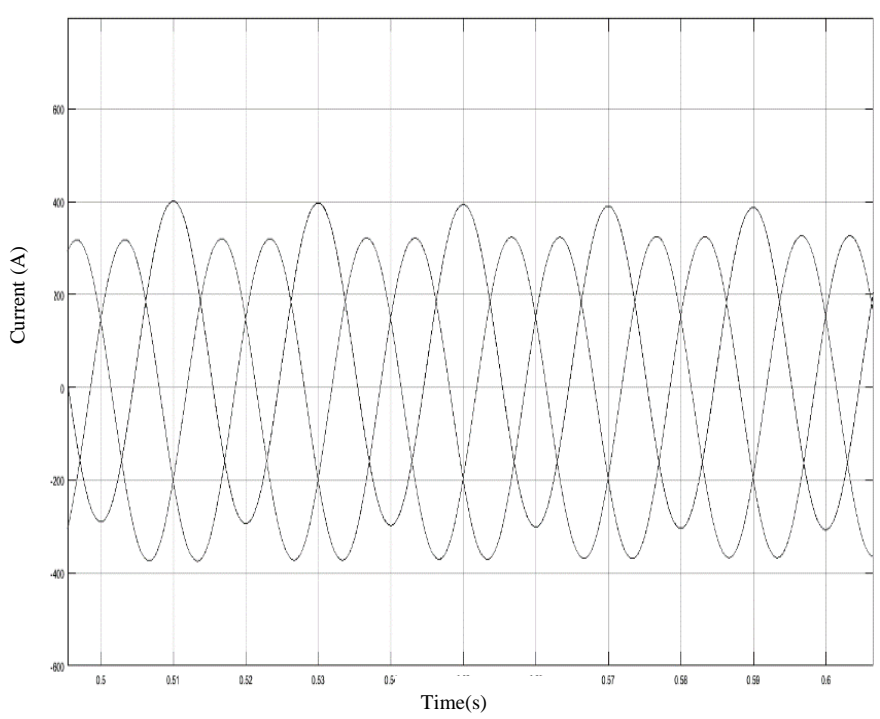

Fig.8. Source current with compensation 


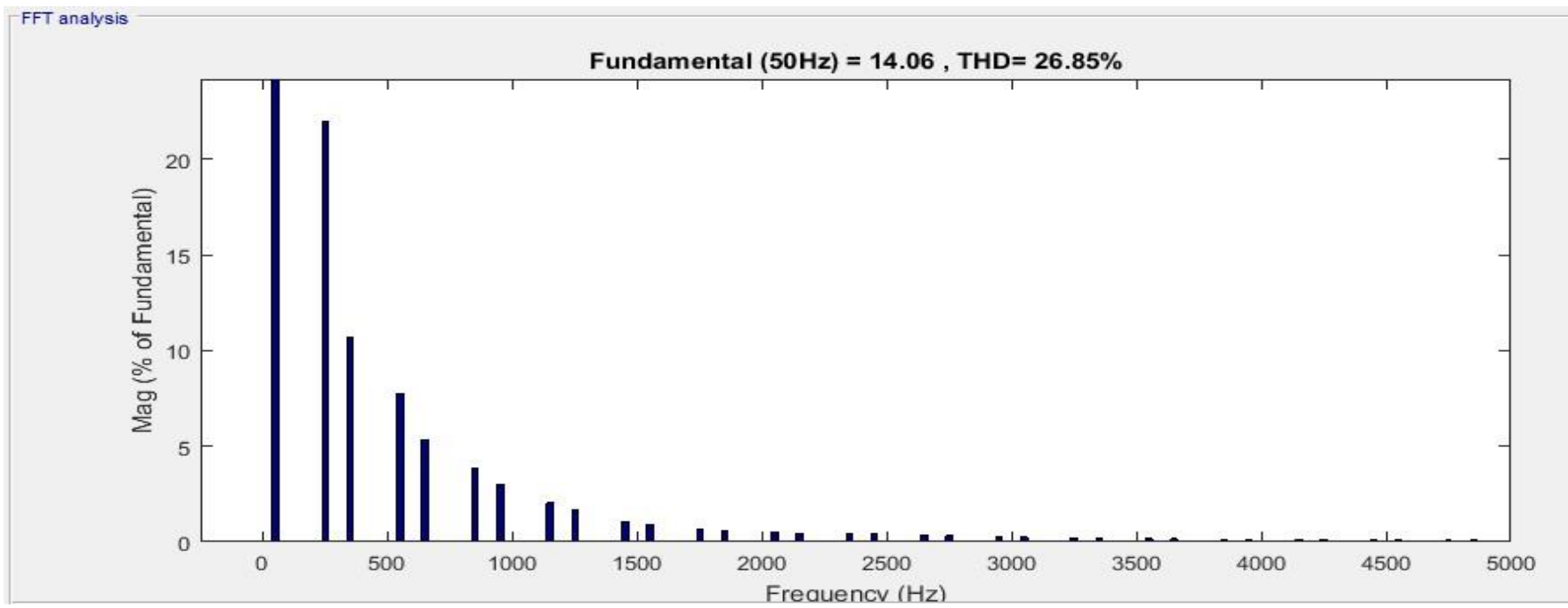

Fig.9. FFT result of Source current without compensation

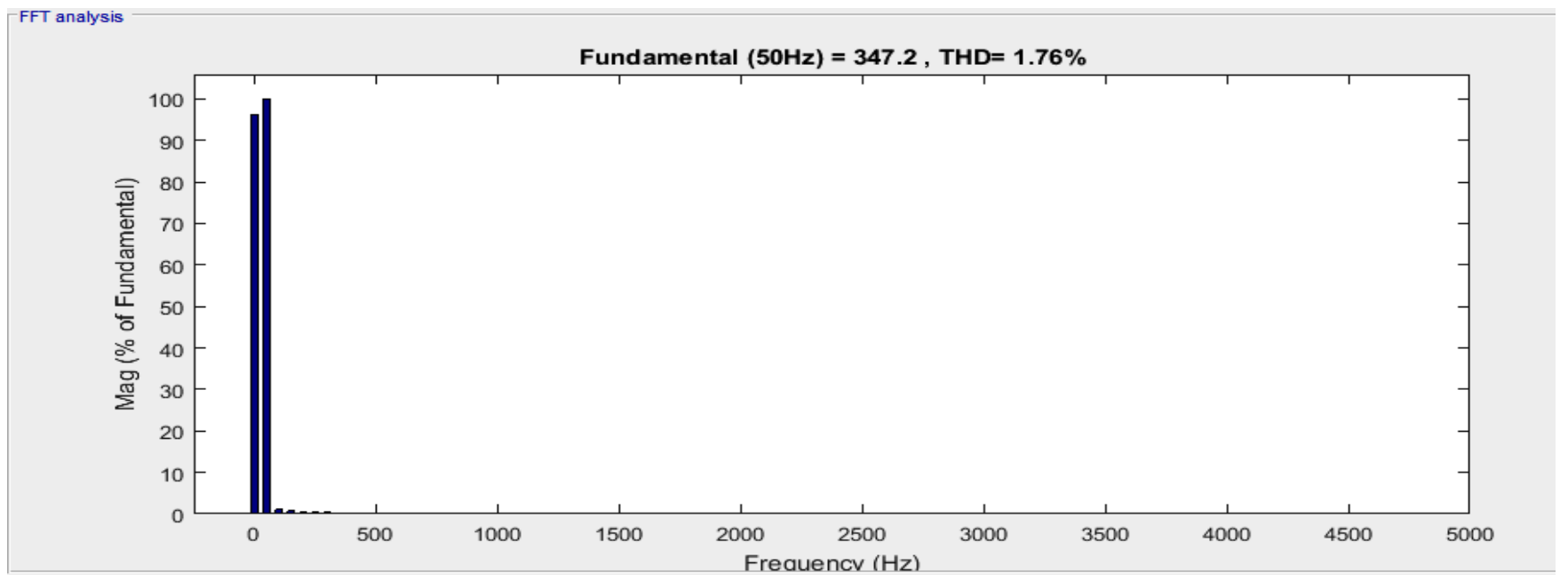

Fig.10. FFT result of Source current with compensation

Table- II: System Parameters

\begin{tabular}{|c|c|c|c|}
\hline $\begin{array}{c}\text { Harmonic } \\
\text { Order }\end{array}$ & $\begin{array}{c}\text { IEEE } \\
\text { Standards }\end{array}$ & $\begin{array}{c}\text { Measured } \\
\text { value without } \\
\text { APF }\end{array}$ & $\begin{array}{c}\text { Measured } \\
\text { value with } \\
\text { APF }\end{array}$ \\
\hline $1^{\text {st }}$ & 100 & 100 & 100 \\
\hline $5^{\text {st }}$ & 4 & 21.99 & 0.38 \\
\hline $7^{\text {st }}$ & 4 & 10.66 & 0.31 \\
\hline $11^{\text {st }}$ & 2 & 7.73 & 0.17 \\
\hline $13^{\text {st }}$ & 2 & 5.35 & 0.14 \\
\hline $17^{\text {st }}$ & 1.5 & 3.87 & 0.15 \\
\hline $19^{\text {st }}$ & 1.5 & 2.99 & 0.13 \\
\hline THD & $\mathbf{5}$ & $\mathbf{2 6 . 8 5}$ & $\mathbf{1 . 7 6}$ \\
\hline
\end{tabular}

\section{CONCLUSION}

A fuzzy logic based current controlled shunt APF is developed with VSI based converter and analysedduring this paper. The aim is to mitigateloadside current harmonic, to scale back THD in system was achieved. With the help of fuzzy logic controller, the performance of shunt APF is improved. The result shows the effectiveness of proposed FLC based shunt active power filter in mitigate current harmonic. The THD is limit to $1.76 \%$ from $26.85 \%$ by FLC based shunt APFand is found under the bounders of IEEE standard 519-1992. The implementation of fuzzy system makes the course of compensation easy with fewer number of sensors.

\section{REFERENCES}

1. B. Singh, K. Al-Haddad and A. Chandra, "A review of active filters for power quality improvement," in IEEE Transactions on Industrial Electronics, vol. 46, no. 5, pp. 960-971, Oct. 1999.

2. B. Singh, K. Al-Haddad and A. Chandra, "Power Quality Problems and Mitigation Techniques", first edition, John Wiley and sons Ltd, 2015.

3. L. S. Czarnecki, "Instantaneous reactive power p-q theory and power properties of three-phase systems," in IEEE Transactions on Power Delivery, vol. 21, no. 1, pp. 362-367, Jan. 2006.

4. M. Jauhari, K. Widarsono and A. A. Kurdianto, "Shunt Active Power Filter for Harmonic Mitigation based on P-Q Theory," 2019 International Conference on Electrical, Electronics and Information Engineering (ICEEIE), Denpasar, Bali, Indonesia, 2019, pp. 11-14.

5. S. Gautam and M. Aeidapu, "Sine Cosine Algorithm Based Shunt Active Power Filter For Harmonic Compensation," 2019 3rd International conference on Electronics, Communication and Aerospace Technology (ICECA), Coimbatore, India, 2019, pp. 10511056.

6. E. M. Thajeel, M. M. Mahdi and E. I. Abbas, "Fuzzy logic controllerbased Shunt Active Power Filter for Current Harmonic Compensation," 2020 International Conference on Computer Science and Software Engineering (CSASE), Duhok, Iraq, 2020, pp. 94-99.

7. S. Musa, M. A. M. Radzi, H. Hisham and N. I. Abdulwahab, "Fuzzy logic controller based three phase shunt active power filter for harmonics reduction," 2014 IEEE Conference on Energy Conversion (CENCON), Johor Bahru, 2014, pp. 371-376.

Published By:

Blue Eyes Intelligence Engineering

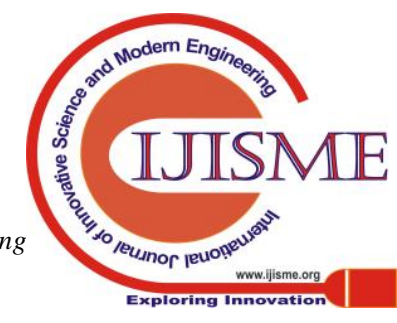


8. N. Gupta, S. P. Singh and S. P. Dubey, "Fuzzy logic controlled shunt active power filter for reactive power compensation and harmonic elimination," 2011 2nd International Conference on Computer and Communication Technology (ICCCT-2011), Allahabad, 2011, pp. 8287.

9. IEEE standard 519-1992, IEEE recommended practices and requirement for harmonic control in electrical power systems, IEEE, Inc. 1993.

\section{AUTHORS PROFILE}

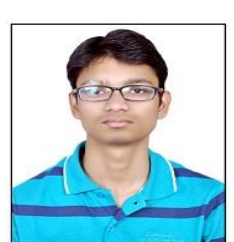

Aditya Vishwakarma, Research Scholar in Power System \& Control, Electrical Engineering Department, SGSITS, 23 Park Road Indore452003. He received his Bachelor degree in the Electrical and Electronics engineering from Oriental College of Technology, Bhopal-462021 in 2017. His area of research interests includes and renewable energy. power quality, power system optimization, AI

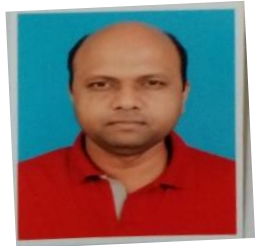

R. S. Mandloi, has obtained his B.E. in Electrical Engineering from Shri G. S. Institute of Technology \& Science (SGSITS), Indore, in 2003. He has obtained his M. E. in Electrical Engineering with the specialization of Power Electronics from Shri G. S. Institute of Technology \& Science (SGSITS), Indore, in 2006. He joined the department of Electrical Engineering, SGSITS, Indore, in 2006, where he is currently an assistant professor. He is working in the area of power electronics, electrical drives and power quality. 